\title{
Sustainability science: bridging the gap between science and society
}

\author{
Arnim Wiek • Francesca Farioli • Kensuke Fukushi • \\ Masaru Yarime
}

Received: 20 December 2011/Accepted: 20 December 2011/Published online: 17 January 2012

(C) Springer 2012

Sustainability scientists continue to struggle with overcoming the reactive environmental protection paradigm and focusing on the urgent and complex challenges that threaten the long-term vitality and integrity of societies around the globe (Rayner 2011). ${ }^{1}$ These challenges are no longer ignorable, as they have triggered fierce debates and controversies across all sectors and classes of society, finally infiltrating the ivory towers of academia. Yet, public attention is captivated by the entertaining media episodes on these catastrophes and hardly any attention is paid to the catastrophes' underlying structures and root causes. Recent examples include Fukushima's nuclear power plant fiasco and the BP oil spill in the Gulf of Mexico that divert attention from the key drivers, namely, the insatiable energy consumption in industrialized nations; the economic ideologies of safety and security that justify military interventions and arms trade, which continue to increase and spread in spite of humanitarian rhetoric and global

\footnotetext{
A. Wiek $(\bowtie)$

School of Sustainability, Arizona State University,

Tempe, AZ 85287-5502, USA

e-mail: arnim.wiek@asu.edu

F. Farioli

CIRPS Interuniversity Research Centre for Sustainable

Development, Sapienza University of Rome,

Piazza San Pietro in Vincoli, 10, 00184 Rome, Italy
}

K. Fukushi

Integrated Research System for Sustainability Science (IR3S),

The University of Tokyo, 7-3-1 Hongo, Tokyo 113-8654, Japan

\section{Yarime}

Graduate Program in Sustainability Science (GPSS),

The University of Tokyo, Kashiwanoha 5-1-5, Kashiwa,

Chiba 277-8563, Japan recession; the continuous urbanization, with the majority of the world's population now living in urban areas, thereby, perpetuating the discredits and exploits of rural areas; the silent discounting of our children's future through industrial food, resulting in more than a quarter of all children in industrialized nations being obese or overweight, with the majority staying obese as adults (Wiek et al. 2011b).

While research and education slowly recognize the importance of shifting their efforts to such challenges and their root causes (Jerneck et al. 2011; Spangenberg 2011; Wiek et al. 2011a), sustainability scientists lack experience and expertise in contributing to feasible and effective solution options. The concept of linking knowledge to action for sustainability was initiated a decade ago (Kates et al. 2001) and has been reiterated since then (Komiyama and Takeuchi 2006; van Kerkhoff and Lebel 2006); yet, too many scholars still believe that this link will miraculously emerge. However, it is obvious that it requires a very different type of research and education (Sarewitz et al. 2010; Wiek et al. 2011a): namely, research that generates knowledge that matters to people's decisions and engages in arenas where power dominates knowledge; and education that enables students to be visionary, creative, and rigorous in developing solutions and that leaves the protected space of the classroom to confront the dynamics and contradictions of the real world.

Against this background, the community of sustainability scientists is confronted with two essential questions. First, what is a reasonable mission for sustainability science, considering that research and education are valuable but not sufficient contributions to solving sustainability

\footnotetext{
${ }^{1}$ Steve Rayner's communication at the "Accelerating Sustainability" conference at the Center for Interactive Research on Sustainability (CIRS), University of British Columbia, Vancouver, BC, Canada, November 4, 2011.
} 
problems? Second, recognizing these constraints, how can sustainability science optimally contribute to solving sustainability problems, and what are the necessary changes in personal attitudes and institutional structures to support these efforts? In response to these questions, it has widely been recognized that collaboration and partnerships with and across different stakeholder groups are critical conditions for sustainability science and its real-world impacts (Blackstock et al. 2007; Whitmer et al. 2010; Spangenberg 2011; Talwar et al. 2011).

This Special Issue focuses on the opportunities and challenges of these partnerships as a means toward transformational change. The Special Issue stems from and expands on the outcomes of the 2nd International Conference on Sustainability Science (ICSS 2010) that took place in Rome, Italy, June 23-25, 2010, organized by the Interuniversity Research Centre for Sustainable Development (CIRPS) at Sapienza University of Rome, in collaboration with the Integrated Research System for Sustainability Science (IR3S), the United Nations University, and Arizona State University. ${ }^{2}$ Embedded in a broad review of the state of sustainability science, the conference focused specifically on how sustainability science can leverage and alter the current relations between research, business, government, and civil society to develop and implement solution options to sustainability challenges. The ICSS 2010 addressed these issues in plenary sessions, through a workshop for doctoral students, and an open deliberative session among representatives from research, industry, and civil society. The conference was opened by Elinor Ostrom (with a video message in an interview style), highlighting the importance of systemic problem analysis, developing multiple synergistic solutions, and learning from failuresall of which needs to happen in strong partnerships across different stakeholder groups. ${ }^{3}$

The articles compiled in this Special Issue shed light on different themes and facets of these collaborative efforts. The first two articles address epistemological and methodological challenges specific to sustainability science projects. The article by Wiek et al. (2012) presents a comparative appraisal of five representative sustainability science projects, using a set of accepted evaluative criteria derived from theoretical and conceptual studies. The results indicate project accomplishments regarding problem focus and basic transformational research methodology, but also highlight deficits regarding stakeholder participation, actionable results, and larger impacts. The article details potential improvements of the evaluated projects to seize the full potential of transformational sustainability science. While this article identifies multi-

\footnotetext{
${ }^{2}$ See http://icss2010.net.

${ }^{3}$ See http://sustainability.asu.edu/research/profiles/ostrom.php.
}

stakeholder collaboration as a general methodological and procedural challenge in sustainability science projects, the article by Lang et al. (2012) systematically explores collaborative (transdisciplinary) procedures and principles. The authors illustrate the barriers to implementing these principles in various sustainability science projects from around the world. The results suggest that there is convergence towards general design principles for transdisciplinary sustainability research, but that a great deal of experience is necessary in order to cope with the various potential pitfalls that can undermine impactful collaboration. The article concludes with a plea for more evaluative and comparative studies that make transdisciplinary experiences and insights accessible and applicable for the growing community of sustainability scholars and practitioners.

The next three articles explore different collaborative settings. The article by Shiroyama et al. (2012) explores general multi-agent governance efforts towards sustainability. It critically discusses different forms and levels of collaboration and the role of knowledge integration. Challenges and coping strategies are illustrated by means of two cases studies, one on reducing emission from deforestation and forest degradation, and one on global phosphorous management. The article by Orecchini et al. (2012) analyzes university-industry collaboration for a transition towards sustainability, based on scientific frameworks and practical experience gained from concrete collaborative processes. The article concludes with recommendations for successful collaboration within the framework of sustainability science, including pragmatic methods for knowledge integration, multi-year collaborations, inclusive communication, and impact assessments of collaborations. The article by Benessia et al. (2012) critically reflects on the current dominant concept of sustainability science and outlines an innovative conceptualization through a plurality of epistemologies, languages, styles of research, experiences, and actions. The article explores a scenario in which sustainability is fruitfully hybridized with a plurality of artistic and cultural expressions and modes of experience-based knowledge; this hybrid is suggested as a new kind of collective diagnose and praxis for addressing sustainability challenges.

The following article by Han et al. (2012) can be framed as an exploration of how the aforementioned partnerships could be utilized in addressing challenges of urban sustainability. It outlines a sustainable urban future by means of a low-carbon society, coping with extended life expectancy, and bridging the urban-rural divide. The article highlights the valuable insights that might result from such visioning efforts, but also acknowledges the limitations of the proposed vision, including its exclusive suitability only for highly industrialized regions like Japan or central 
Europe, and that its implementation might come with some unintended negative consequences.

The article by Yarime et al. (2012) extends the previous insights into the realm of sustainability education. It explores how sustainability programs at different universities prepare their students for established and novel career trajectories, in which collaborative and integrative capacity and competence gain more and more relevance. Academic development, institutionalization, and collaboration with stakeholders need to be implemented in academic programs in coherent ways. A key insight from this article is that the academic educational system, which is largely not designed to train students to become agents and innovators for social change, requires fundamental reforms rather than incremental adjustments in order to seize the full potential of sustainability science. The integration of education, research, and contributions to society will be of particular importance in transforming higher educational institutions for sustainability.

Finally, the article by van der Leeuw et al. (2012) takes a critical and provocative view at academia in its attempt to become relevant in sustainability efforts. The diagnosis is deflating: anachronistic pedagogy, mismatched incentives, and insular products and communications that leave academic institutions poorly positioned to contribute significantly to solving sustainability problems. The paper points out that rhetoric still outweighs contributions to real-world sustainability transitions, while acknowledging that sustainability science offers new inclusive methods of research and practices involving relevant communities throughout problem-solving processes in meaningful ways. Innovations and reforms in academia need to cut deep and be fast in order to successfully and sustainably compete against the everaccelerating destruction of societies and environments.

Sustainability science holds a promise - to children and future generations, to marginalized and disenfranchised groups, to the environment (beyond materials and energy fluxes). But as the first decade of its inauguration comes to a closure (Kates et al. 2001), it is time to honestly and critically review the achievements and failures in sustainability science: where do we stand in fulfilling this promise, and are we trying hard and smart enough? This Special Issue pays particular attention to the link between science and society in sustainability efforts and indicates some accomplishments. Yet, it mainly suggests that current sustainability science efforts do not sufficiently engage with the affected and responsible stakeholder groups, and fail in contributing significantly to solution options and transformational change. The articles compiled here outline various ways forward, including innovative epistemologies and methodologies (from problem-focused to solution-focused research; from searching what to do, to determining how to do it; from the power of techno-science to new kinds of hybrid knowledge and practice through extended participatory processes), institutional reforms (incentives and reward structures for researchers and practitioners), and novel training schemes (not only for students but also for faculty and practitioners). A key success factor for moving forward with a transformational sustainability science agenda is the creation and strengthening of local, regional, and global networks of researchers and practitioners that are willing to set aside disparities in power, authority, and reputation in order to make demonstrable progress towards sustainability.

Acknowledgments The guest editors would like to thank the Editor-in-Chief Professor Kazuhiko Takeuchi for the opportunity and the encouragement to edit this Special Issue as well as Darek Gondor and Osamu Saito (Editorial Office) for tireless and competent support during the editorial process.

\section{References}

Benessia A, Funtowicz S, Bradshaw G, Ferri F, Medina CP, RaezLuna EF (2012) Hybridizing sustainability: towards a new praxis for the present human predicament. Sustain Sci 7(Suppl). doi: 10.1007/s11625-011-0150-4

Blackstock KL, Kelly GJ, Horsey BL (2007) Developing and applying a framework to evaluate participatory research for sustainability. Ecol Econ 60:726-742

Han J, Fontanos P, Fukushi K, Herath S, Heeren N, Naso V, Cecchi C, Edwards P, Takeuchi K (2012) Innovation for sustainability: towards a sustainable urban future. Sustain Sci 7(Suppl). doi: 10.1007/s11625-011-0152-2

Jerneck A, Olsson L, Ness B, Anderberg S, Baier M, Clark E et al (2011) Structuring sustainability science. Sustain Sci 6:69-82

Kates RW, Clark WC, Corell R, Hall JM, Jaeger CC, Lowe I et al (2001) Sustainability science. Science 292(5517):641-642

Komiyama H, Takeuchi K (2006) Sustainability science: building a new discipline. Sustain Sci 1(1):1-6

Lang DJ, Wiek A, Bergmann M, Stauffacher M, Martens P, Moll P, Swilling M, Thomas C (2012) Transdisciplinary research in sustainability science-practice, principles and challenges. Sustain Sci 7(Suppl). doi:10.1007/s11625-011-0149-x

Orecchini F, Valitutti V, Vitali G (2012) Industry and academia for a transition towards sustainability: advancing sustainability science through university-business collaboration. Sustain Sci 7(Suppl). doi:10.1007/s11625-011-0151-3

Sarewitz D, Kriebel D, Clapp R, Crumbley C, Hoppin P, Jacobs M et al (2010) The sustainable solutions agenda. Consortium for Science, Policy and Outcomes (CSPO), Arizona State University and Lowell Center for Sustainable Production, University of Massachusetts, Lowell

Shiroyama H, Yarime M, Matsuo M, Schroeder H, Scholz R, Ulrich A (2012) Governance for sustainability: knowledge integration and multi actor dimensions. Sustain Sci 7(Suppl). doi:10.1007/ s11625-011-0155-Z

Spangenberg JH (2011) Sustainability science: a review, an analysis and some empirical lessons. Environ Conserv 38:275-287

Talwar S, Wiek A, Robinson J (2011) User engagement in sustainability research. Sci Public Policy 38:379-390

van der Leeuw S, Wiek A, Harlow J, Buizer J (2012) How much time do we have? Urgency and rhetoric in sustainability science. Sustain Sci 7(Suppl). doi:10.1007/s11625-011-0153-1 
van Kerkhoff L, Lebel L (2006) Linking knowledge and action for sustainable development. Annu Rev Environ Resour 31:445-477

Whitmer A, Ogden L, Lawton J, Sturner P, Groffman PM, Schneider L et al (2010) The engaged university: providing a platform for research that transforms society. Front Ecol Environ 8(6): 314-321

Wiek A, Withycombe L, Redman CL (2011a) Key competencies in sustainability: a reference framework for academic program development. Sustain Sci 6:203-218

Wiek A, Withycombe L, Redman CL, Banas Mills S (2011b) Moving forward on competence in sustainability research and problem solving. Environ Sci Policy Sustain Dev 53:3-13
Wiek A, Ness B, Brand FS, Schweizer-Ries P, Farioli F (2012) From complex systems analysis to transformational change: a comparative appraisal of sustainability science projects. Sustain Sci 7(Suppl). doi:10.1007/s11625-011-0148-y

Yarime M, Trencher G, Mino T, Scholz RW, Olsson L, Ness B, Frantzeskaki N, Rotmans J (2012) Establishing sustainability science in higher education institutions: towards an integration of academic development, institutionalization, and collaborations with stakeholders. Sustain Sci 7(Suppl). doi:10.1007/ s11625-011-0157-5 